\title{
SPECIFIC PLANT INDUCED BIOFILM FORMATION IN METHYLOBACTERIUM SPECIES
}

\section{Priscilla B. Rossetto ${ }^{1 *}$, Manuella N. Dourado ${ }^{2}$, Maria C. Quecine ${ }^{2}$, Fernando D. Andreote ${ }^{3}$, Welington L. Araújo ${ }^{4}$, João L.} Azevedo $^{2}$, Aline A. Pizzirani-Kleiner ${ }^{2}$

${ }^{1}$ Laboratório de Biotecnologia Vegetal, Centro de Energia Nuclear na Agricultura Universidade de São Paulo, Piracicaba, SP, Brasil; ${ }^{2}$ Departamento de Genética, Escola Superior de Agricultura "Luiz de Queiroz", Universidade de São Paulo, Piracicaba, SP, Brasil; ${ }^{3}$ Departamento de Ciência do Solo, Escola Superior de Agricultura "Luiz de Queiroz", Universidade de São Paulo, Piracicaba, SP, Brasil; ${ }^{4}$ Núcleo Integrado em Biotecnologia, Universidade de Mogi das Cruzes, Mogi das Cruzes, SP, Brasil.

Submitted: July 22, 2010; Returned to authors for corrections: September 27, 2010; Approved: March 14, 2011.

\begin{abstract}
Two endophytic strains of Methylobacterium spp. were used to evaluate biofilm formation on sugarcane roots and on inert wooden sticks. Results show that biofilm formation is variable and that plant surface and possibly root exudates have a role in Methylobacterium spp. host recognition, biofilm formation and successful colonization as endophytes.
\end{abstract}

Key words: Methylobacterium, endophytes, biofilm; sugarcane

The genus Methylobacterium belongs to the $\alpha$ proteobacteria and comprises more than 34 described species (6). Members of this genus degrade one-carbon compounds (C1) such as methanol and methylamine (8) and are widely distributed in the environment, colonizing soil, water, leaf surfaces, nodules, seeds, air, and sediments (9). They have been shown to interact symbiotically with different plant species of agronomic importance (2, 3, 5). Specifically in sugarcane, Methylobacterium spp. are important endophytes described as responsible for increased seed germination, leaf area, plant height and number of internodes (4). Better understanding of Methylobacterium spp. colonization of plants is desirable for sustaining and improving their use as plant growth promoters (5). The aim of this study was to investigate the role of the living plant surface in biofilm formation by $M$. extorquens and M. mesophilicum strains and to demonstrate that these strains differ in their requirements for biofilm formation.

The strains SR1.6/6 (M. mesophilicum) and AR1.6/2 (M. extorquens) used in this study belong to the collection of the Laboratory of Microbial Genetics (ESALQ/USP, Piracicaba, SP). They were previously isolated from citrus and characterized (3). These strains were commonly cultivated in 5 mL CHOI 3 medium (8) for 96 hours on a rotary shaker at 150 rpm and $28^{\circ} \mathrm{C}$. Bacterial fresh culture were harvested by centrifugation (10 min at $10000 \mathrm{xg}$ ) and the pellet subsequently resuspended and diluted in PBS (phosphate-buffered saline, $\mathrm{pH} 7.4)$ to $10^{6} \mathrm{CFU} \mathrm{mL}^{-1}$ for plant inoculation. For bacterial inoculation, sugarcane seedlings (variety SP80 3280, kindly supplied by the Centro de Tecnologia Canavieira - CTC, 
Piracicaba, SP, Brazil) were maintained in vitro. They were placed in sterile tubes $(50 \mathrm{~mL})$ containing $7 \mathrm{~mL}$ of Murashige and Skoog (MS) medium (7) and bacteria were added to a final

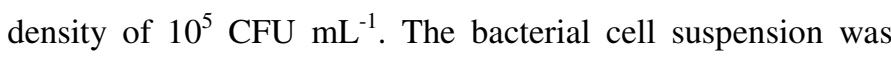
incubated with the seedling roots for 2,10 and 18 days at $28^{\circ} \mathrm{C}$. Commercial wooden sticks were used with the same conditions as a control. At different days after inoculation (DAI), samples were taken and observed by Scanning Electron Microscope (SEM) (2 and $6 \mathrm{DAI}$ - plants; 3, 10 and $18 \mathrm{DAI}$ - wood sticks) and re-isolation analyses were done (2, 10 and 17 DAI plants). Three repetitions of each treatment were used.

In order to determine biofilm formation capability of the two strains, wooden sticks and sugarcane seedling roots samples were placed in a $8 \%(\mathrm{v} / \mathrm{v})$ glutaraldehyde solution in 2 $\mathrm{M}$ sodium cacodylate buffer $(\mathrm{pH}$ 7.2) and kept till further processing. Subsequently samples were dehydrated in an acetone series (30, 50, 70, 90 and 100\%) and dried by critical point drying in a Balzers CPD 050. After covering with gold (metalizator MED 010 - Balzers), the samples were visualized in Scanning Electron Microscope (LEO-Zeiss) at NAP/MEA (ESALQ/USP). Andreote et al. (1) have shown that SR1.6/6 produces biofilms on the root surfaces of periwinkle and tobacco seedlings prior to endophytic colonization. Here we have investigated whether the strains might have different capacities for forming biofilms on different surfaces, thus possibly determining their ability to become endophytic colonizers of sugarcane plants.

Our observations of wooden sticks showed biofilm formation only by $M$. extorquens AR1.6/2 (Figure 1A, 1B and 1C). Cells of M. mesophilicum SR1.6/6 were observed at all sampling times, but formation of an exopolymer layer was not observed (Figure 1F, 1G and 1H); just isolated cells (Figure 1F - arrow). Biofilm formation by the strain AR1.6/2 was characterized by its typical organization of bacterial cells on the wooden surface and by the presence of EPS (Figure 1C arrow), produced and released by the bacteria forming the biofilm. It is remarkable that, even after a short period of incubation (3 DAI) the treatment with the strain AR1.6/2 already resulted in an organized biofilm (Figure 1A). The formation of biofilm on an inert material (such as the wooden stick used here) shows that biofilm formation of strain AR1.6/2 does not require plant-derived factors.

On the sugarcane seedling roots, biofilm formation by both strains (AR1.6/2 and SR1.6/6) were observed at all sampled periods (2 and 6 DAI) (Figure 1D, 1E, 1I and 1J). In contrast to what was observed for wooden sticks, strain SR1.6/6 was able to form biofilm covering the sugarcane roots, suggesting that biofilm formation of this strain does require plant-derived factors. In the control treatment (without bacterial cells inoculation) of all experiments no bacteria were observed by similar material preparation and SEM scanning (data not shown).
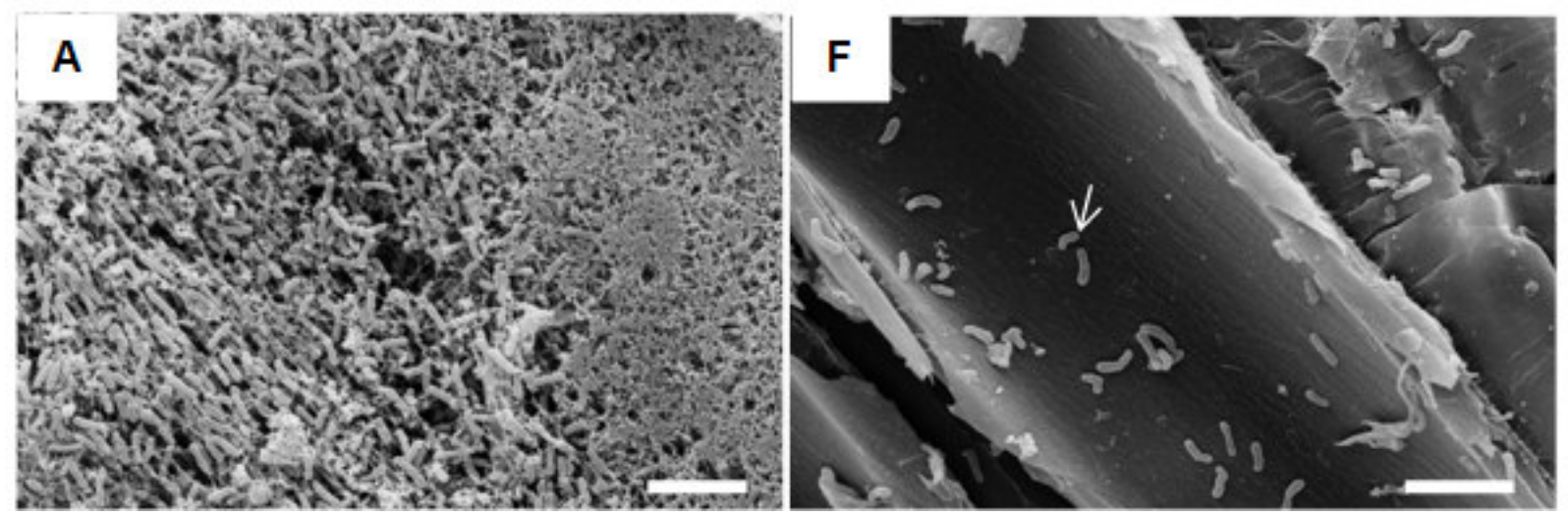

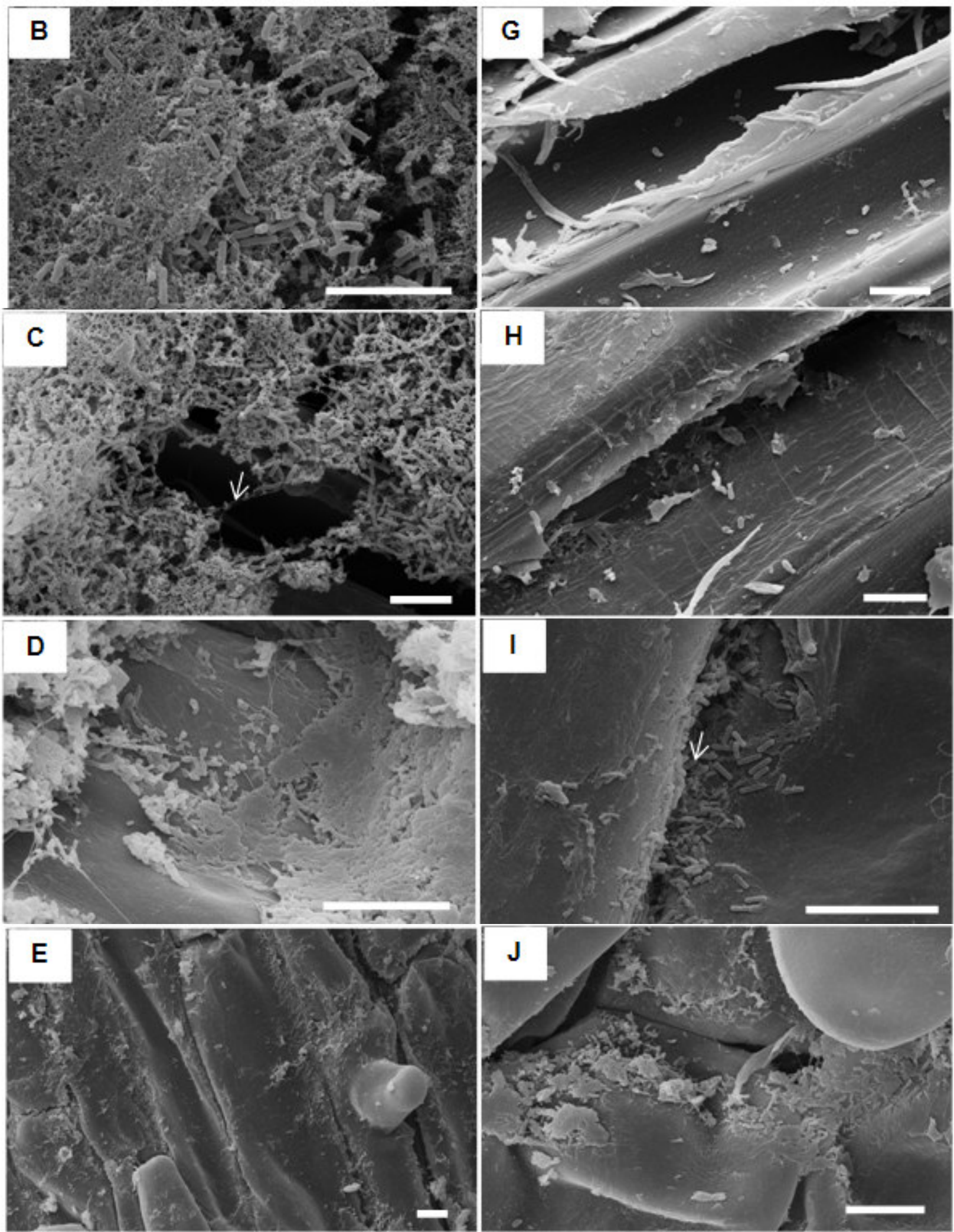

Figure 1. Methylobacterium extorquens (AR1.6/2 - first column) and Methylobacterium mesophilicum (SR1.6/6 - second column) on the surface of wood stick (A-C and F-G) and on the surface of sugarcane in vitro plants (D-E and I-J). The samples were collected three times on the wood stick (A, F-3 DAI; B, G-10 DAI; C, H-18 DAI) and two times on plants (D, I-2 DAI; E, J-6 DAI). 
Quantification of the Methylobacterium spp. by reisolation allowed an estimation of the populations for each strain in association with roots (surface or endophytic) and inside shoot tissues of sugarcane (Figure 2). For quantification, roots of the plants were submerged in $2 \mathrm{~mL}$ of PBS and agitate at $120 \mathrm{rpm}$ for 1 hour with the shoots remaining above the buffer. The resulting cell suspension was diluted and plated to quantify the bacteria in CHOI 3. Subsequently, the plant material was removed from tubes and submitted to surface disinfection (1 min ethanol 70\%, 3 min sodium hypochlorite $2 \%$, three sterile water rinsings). The disinfected material was separated in root and shoot, weighed and grinded in $2 \mathrm{~mL}$ of PBS buffer. The resulting suspension was also diluted and plated on CHOI 3 medium in order to estimate the numbers of colonizing bacteria. All plates were incubated at $28^{\circ} \mathrm{C}$ and colony development was monitored during 14 days.

Cells of both strains were detectable in all samples at the earliest sampling time point (2 DAI) (Figure 2) indicating that they are both able to colonize the root surface as well as enter plant tissues and spread from root to shoot. However, the strains differed strongly in the further course of the experiment. AR1.6/2 entered the plant and colonized the shoot faster than SR 1.6/6 (2 DAI, Figure 2C). However, after this fast colonization, the endophytic population decreased in shoot tissues, and became more restricted to roots (Figures $2 \mathrm{~A}$ and 2B). The scenario for SR1.6/6 was quite distinct from the previous one. This strain more rapidly proliferated inside the root and eventually endophytically colonized shoot tissue at high density, whereas strain AR1.6/2 could not maintain a population there.

In summary, we have observed in the two bacterial strains two distinct behavior to biofilm formation and sugarcane colonization. Extensive and plant-independent biofilm formation by AR1.6/2 did not result in successful colonization of areal plant parts. In contrast, strain SR1.6/6 whose biofilm formation was induced by the plant root, and more restricted to root cell-cell borders (Figure 2I - arrow), was a more successful endophytic colonizer of sugarcane seedling shoots. This is in line with the earlier observed colonization pattern of this bacterium, entering plant tissues by the intercellular spaces (1). Plant-independent biofilm formation was not a prerequisite for successful endophytic colonization of shoot tissue. Plant tissue architecture or localized exudation from these areas could play a role in this specific pattern of colonization and thus play a role in determining the outcome of the colonization by bacteria. A more extensive study of biofilm and colonization behavior of a larger variety of strains will be necessary to corroborate this suggested correlation.

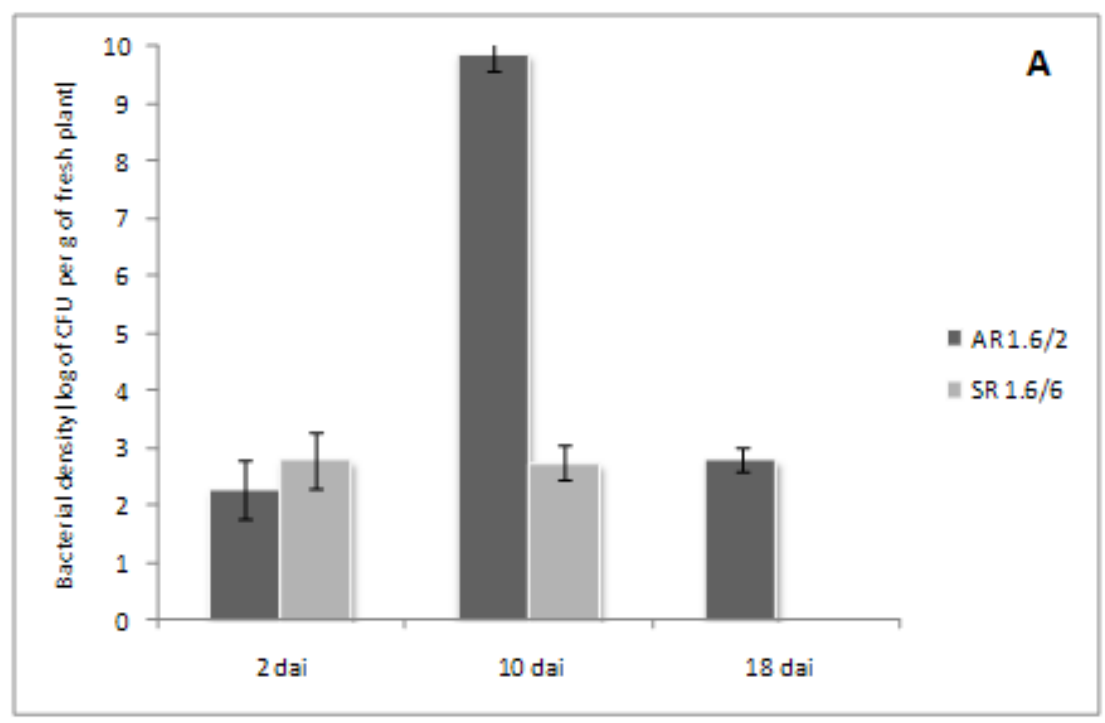



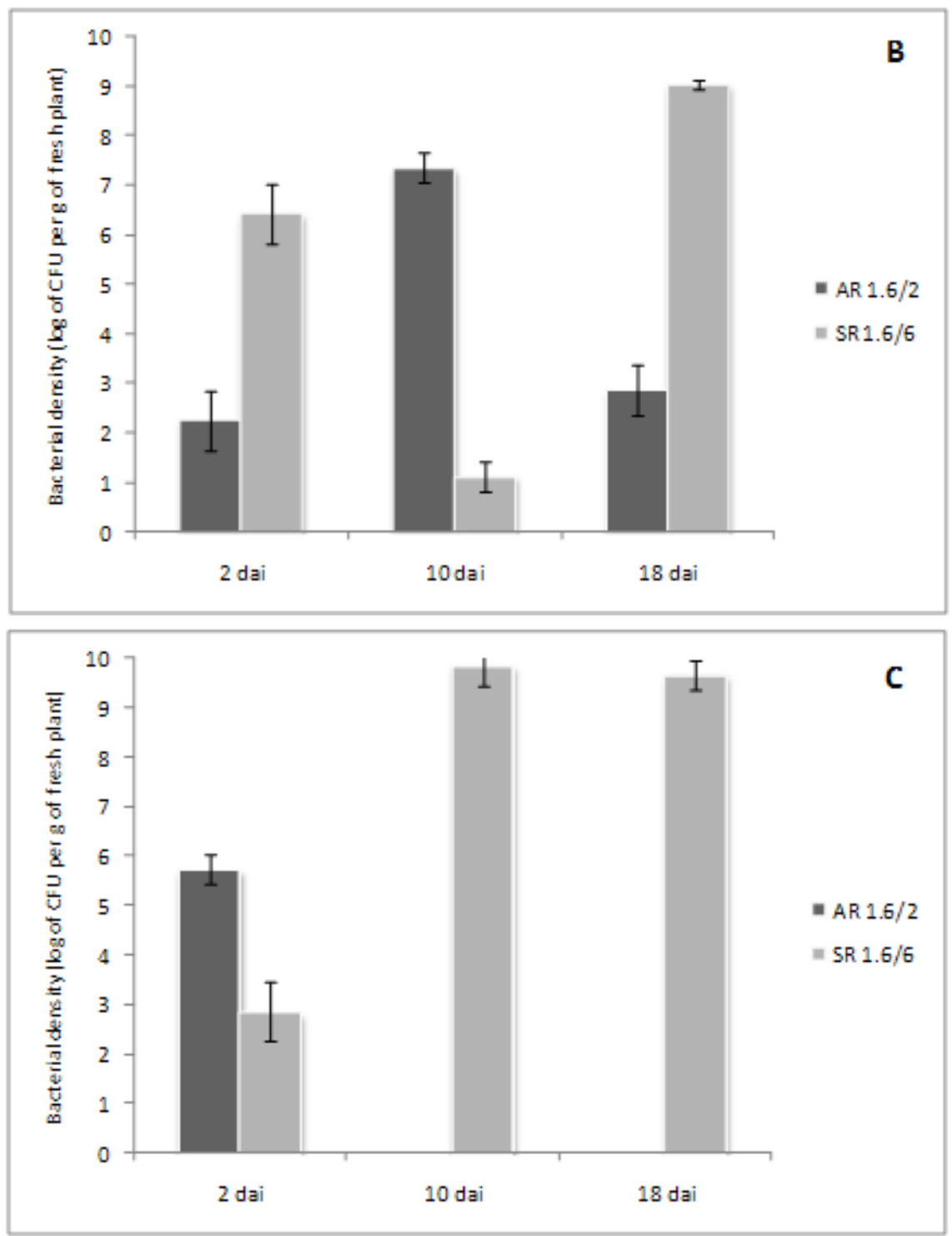

Figure 2. Quantification of the bacterial density for strains AR1.6/2 (M. extorquens) and SR1.6/6 (M. mesophilicum) in association with sugarcane plants cultivated in vitro. Data are presented for sampling made after two, 10 and 18 days after inoculation (DAI)of stem (A). root (B) and rhizosphere (C). Columns represent the average of three biological replications, and bars indicate the standard deviation obtained from replications.

\section{ACKNOWLEDGEMENTS}

This project was supported by grants from FAPESP (PB Rossetto, M Dourado, MC Quecine) and CNPq (FD Andreote). We would like to thank Dr. Ruud de Maagd for his large contribuition to review the work. We also thank EW Kitajima (Department of Plant Pathology and Nematology, Escola Superior de Agricultura "Luiz de Queiroz”, University of São
Paulo) for SEM facilities at NAP/Mepa (Support Center for Electron Microscopy Research Applied to Agriculture).

\section{REFERENCES}

1. Andreote, D.F.; Lacava, P.T.; Gai, C.S.; Araújo, W.L.; Maccheroni,W.; Overbeek, L.S.V.; Elsas, J.D.V.; Azevedo, J.L. (2006) Model plants for studying the interaction between Methylobacterium mesophilicum and 
Xylella fastidiosa. NRC Research Press. 52, 419-426.

2. Andreote, F.D.; Carneiro, R.T.; Salles, J.F.; Marcon, J.; Labate, C.A.; Azevedo, J.L.; Araújo, W.L. (2009) Culture-independent assessment of rhizobiales-related alphaproteobacteria and the diversity of Methylobacterium in the rhizosphere and rhizoplane of transgenic eucalyptus. Microbial Ecol. 57, 82-93.

3. Araújo, W.L.; Marcon, J.; Maccheroni Jr., W; Elsas, J. D.van; Azevedo, J.L. (2002) Diversity of endophytic bacterial populations and their interaction with Xylella fastidiosa in citrus plant. Appl. Environ. Microbiol. 68, 4906-4914.

4. Madhaiyan, M.; Poonguzhali, S.; Lee, H.S.; Hari, K.; Sundaram, S.P.; Sa, T.M. (2005). Pink-pigmented facultative methylotrophic bacteria accelerate germination, growth and yield of sugarcane clone Co86032 (Saccharum officinarum L.). Biol. Fert. Soils. 41, 5.

5. Madhaiyan, M.; Poonguzhali, S.; Sundaram, S.P.; Sa, T. (2006) A new insight into foliar applied methanol influencing phylloplane methylotrophic dynamics and growth promotion of cotton (Gossypium hirsutum L.) and sugarcane (Saccharum officinarum L.). Env. Exp. Bot. 57, 168-176.

6. Madhaiyan, M.; Poonguzhali, S.; Kwon, S.W.; Sa, T.M. (2009) Methylobacterium phyllosphaerae sp. nov., a pink-pigmented, facultative methylotroph from the phyllosphere of rice. Int. J. Syst. Evol. Microbiol. 59, 22-27.

7. Murashige, T.; Skoog, F. (1962) A revised medium for rapid growth and bioassays with tobacco tissue cultures. Physiol. Plant 15 (3), 473-497.

8. Toyama, H.; Anthony, C.; Lidstrom, M.E. (1998) Construction of insertion and deletion mxa mutants of Methylobacterium extorquens AM1 by electroporation. FEMS Microbiol. Lett. 166, 1-7.

9. Van Aken, B.; Peres, C.M.; Doty, S.L.; Yoon, J.M.; Schnoor, J.L. (2004) Methylobacterium populi sp. nov., a novel aerobic, pink-pigmented, facultatively methylotrophic, metane-utilizing bacterium isolated from poplar trees (Populus deltoids x nigra DN34). Microbiology 54, 11911196. 